\title{
IDENTIFIKASI KEPRIBADIAN DALAM PENDEKATAN PEMBELAJARAN DENGAN MENERAPKAN METODE CERTAINTY FACTOR
}

\author{
Gortap Lumbantoruan ${ }^{1}$, Mufria J. Purba ${ }^{2}$ \\ ${ }^{1,2}$ Universitas Methodist Indonesia

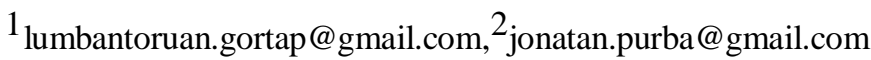

\begin{abstract}
An educator is important to know and understand the personality of a student so that the educational process can take place properly so that it can get maximum results. Because students have different personality types and the personality type of a student shows how students accept the learning material provided by the teacher. In the teaching and learning process, educators who do not understand the personality of students will find it difficult to deliver learning materials that will attract students' interest, which will hamper the knowledge transfer process. In this study, the identification of the personality of students using the certainty factor method and the types of personality analyzed were choleric, melancholic, phlegmatic and sanguinis. Based on the personality traits of each. The goal is to make it easier for educators to find ways to educate according to the personality of students. The results obtained are that by using the certainty factor method, the personality of a student is obtained based on the characteristics of the student with a confidence level of $88.43 \%$.
\end{abstract}

\section{Keywords- Certainty Factor, Personality, Education, Educators, Students.}

\section{PENDAHULUAN}

Sebagaimana diketahui bahwa tujuan pendidikan adalah untuk mengembangkan kecerdasan baik intelektual maupun kecerdasan emosional. Indikator tercapainya tujuan pendidikan pada proses pembelajaran dapat dilihat dari prestasi belajar peserta didik. Secara garis besar hal-hal yang mempengaruhi prestasi belajar dirangkum menjadi faktor internal dan faktor eksternal. Faktor-faktor internal adalah faktor yang mempengaruhi prestasi belajar seseorang yang berasal dari dirinya sendiri, meliputi keseluruhan keadaan fisik maupun psikis. Adapun faktor-faktor eksternal yaitu faktorfaktor yang dapat mempengaruhi prestasi belajar seseorang yang sifatnya berasal dari luar diri seseorang tersebut, meliputi lingkungan keluarga, lingkungan sekolah, dan lingkungan masyarakat [1].

Dalam dunia pendidikan seorang pendidik penting untuk mengetahui dan memahami kepribadian seorang peserta didik agar proses pendidikan bisa berlangsung dengan baik sehingga bisa mendapatkan hasil yang maksimal. Kepribadian merupakan corak perilaku dan kebiasaan individu yang terhimpun di dalam diri seseorang yang digunakan untuk bereaksi, serta menyesuaikan diri terhadap segala rangsangan, baik dari dalam maupun dari luar [2]. Kepribadian merupakan sifat hakiki individu yang tercermin pada sikap dan perbuatannya yang unik, yang membedakan dirinya dengan yang lain. Keunikan tersebut tergantung pada tipe kepribadian [3].

Peserta didik memiliki tipe kepribadian yang berbedabeda dan tipe kepribadian seorang peserta didik menunjukkan bagaimana peserta didik untuk menerima materi pembelajaran yang diberikan oleh pendidik [3]. Dalam proses belajar mengajar pendidik yang tidak memahami kepribadian peserta didik maka akan sulit menyampaikan materi pembelajaran yang akan menarik minat peserta didik yang berdampak kepada proses transfer pengetahuan menjadi terhambat [4].
Permasalahan yang terjadi adalah banyak pendidik yang tidak mengetahui dan memahami kepribadian peserta didik. Hal ini terjadi karena tidak semua pendidik memiliki pengetahuan untuk mendeteksi kepribadian masing-masing peserta didik yang mengakibatkan pendidikan menjadi terhambat dan peserta didik tidak dapat menerima dengan baik materi pembelajaran yang diberikan. Oleh karena itu dibutuhkan suatu sistem yang dapat membantu pendidik untuk mengenal kepribadian peserta didik.

Dalam penelitian ini, metode yang digunakan dalam mengidentifikasi kepribadian peserta didik adalah metode certainty factor. Certainty Factor merupakan suatu metode yang digunakan untuk menyatakaan tingkat kepercayaan sebuah hipotesis berdasarkan bukti atau penilaian dari seeorang, Pada konsepnya, Certainty Factor adalah salah satu teknik yang digunakan untuk mengatasi suatu ketidakpastian dalam pengambilan keputusan. Pemberian nilai untuk pembagian tingkat keyakinan, metode certainty factor dianggap cocok untuk mengetahui seberapa yakin hasil analisis untuk identifikasi kepribadian [5], [6].

\section{TINJAUAN PUSTAKA}

\section{Kepribadian}

Kepribadian adalah keseluruhan sikap, perasaan, ekspresi, tempramen, ciri-ciri khas dan perilaku seseorang. Sikap perasaan ekspresi dan tempramen ini akan terwujud dalam tindakan seseorang jika dihadapkan pada situasi tertentu. Setiap orang mempunyai kecenderungan prilaku yang baku, atau berlaku terus menerus secara konsisten dalam menghadapai situasi yang dihadapi, sehingga menjadi ciri khas pribadinya [7]. Kepribadian berperan penting dalam kehidupan yaitu menggambarkan perilaku, watak, atau pribadi seseorang. Kepribadian mencakup gaya, sikap yang berperan aktif dalam menentukan tingkah 
laku yang menyebabkan seseorang memiliki suatu perilaku konsisten [8].

\section{Tipe Kepribadian}

Berdasarkan pemikiran Hipocrates - Galenus, membagi tipe kepribadian seperti berikut ini [9]:

1. Sanguins (Sanguinic)

Dimana orang yang sanguinis adalah orang yang memiliki tipe kepribadian yang khas seperti hidup mudah berganti haluan, ramah, mudah bergaul, lincah, periang, mudah senyum, dan tidak mudah putus asa.

2. Koleris (Choleric)

Dimana orang yang choleris adalah orang yang memiliki tipe kepribadian yang khas seperti hidup penuh semangat, keras, hatinya mudah terbakar, daya juang besar, optimistis, garang, mudah marah, pengatur, penguasa, pendendam, dan serius.

3. Plegmatis (Phlegmatic)

Dimana orang yang phlegmatis adalah orang yang memiliki tipe kepribadian yang khas seperti tidak suka terburu-buru, tenang, tidak mudah dipengaruhi, setia, dingin, santai dan sabar.

4. Melankolis (Melancholic)

Dimana orang yang melancholis adalah orang yang memiliki tipe kepribadian yang khas seperti mudah kecewa, daya juang kecil, muram, pesimistis, penakut, kaku dan menganggap segala sesuatu amat penting.

\section{Metode Certainty Factor}

Metode certainty factor merupakan nilai parameter klinis untuk menunjukkan besarnya tingkat kepercayaan terhadap suatu data yang memiliki nilai dari 0 hingga 1, dimana hasil dari keduanya tidak selalu berjumlah sama. Perhitungan Certainty Factor (CF) menggunakan $\mathrm{MB}(\mathrm{H} \mid \mathrm{E})$ untuk menggambarkan nilai kepercayaan dari hipotesis $\mathrm{H}$, Gejala $\mathrm{E}$, dan $\mathrm{MD}(\mathrm{H} \mid \mathrm{E})$ untuk nilai ketidakpercayaan dari hipotesis $\mathrm{H}$, Gejala E. Perhitungan tersebut dihasilkan dari nilai hipotesis, gejala, dan juga evidence dari setiap nilai fakta [8]. Metode ini dapat membuktikan apakah suatu fakta itu pasti ataukah tidak pasti yang berbentuk metric dan sangat cocok untuk sistem pakar yang mendiagnosis sesuatu yang belum pasti [9].

\section{METODE PENELITIAN}

\section{Alur Penelitian}

Penyelesaian masalah identifikasi kepribadian ini, peneliti menggunakan metode Certainty Factor untuk menggambarkan nilai kepercayaan terhadap suatu fakta. Adapun langkah-langkahnya dapat dilihat seperti flowchart berikut ini:

1. Menentukan tipe kepribadian dan ciri-ciri kepribadian

2. Mengatur Kaidah Produksi atau representasi pengetahuan serta nilai kepercayaan (MB) dan ketidakpercayaan (MD)

3. Mencari Nilai CF dengan kombinasi MB dan MD

4. Menampilkan hasil identifikasi tipe kepribadian.

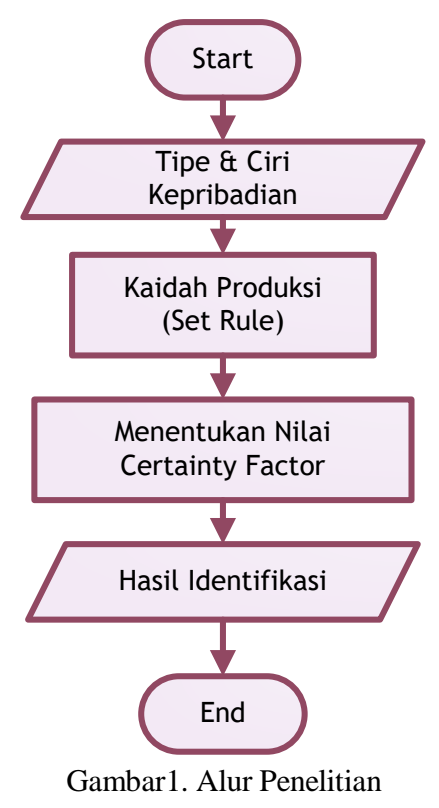

\section{Pengumpulan Data}

Pengumpulan data dalam penelitian ini diperoleh penulis dengan cara library research atau studi pustaka dari berbagai karya ilmiah dengan mempelajari literatur-literatur seperti buku, jurnal, artikel dan lain sebagainya yang relevan dengan penelitian.

\section{Data yang Digunakan}

Data yang digunakan adalah data jenis kepribadian seperti pada tabel berikut:

Tabel 1. Jenis Kepribadian

\begin{tabular}{|l|l|l|}
\hline No & \multicolumn{1}{|c|}{ Jenis } & \multicolumn{1}{|c|}{ Keterangan } \\
\hline K1 & Choleric & $\begin{array}{l}\text { Dicirikan dengan pemilikan } \\
\text { temperamen cepat marah, } \\
\text { mudah tersinggung, dan tidak } \\
\text { sabar. }\end{array}$ \\
\hline K2 & Melancholic & $\begin{array}{l}\text { Memiliki temperamen } \\
\text { pemurung, pesimis, mudah } \\
\text { sedih dan mudah putus asa }\end{array}$ \\
\hline K3 & Phlegmatic & $\begin{array}{l}\text { Bertemperamen yang serba } \\
\text { lamban, pasif, malas, dan } \\
\text { kadang apatis/ masa bodoh }\end{array}$ \\
\hline K4 & Sanguinis & $\begin{array}{l}\text { Memiliki temperamen dan } \\
\text { sifat periang, aktif, dinamis, } \\
\text { dan cekatan. }\end{array}$ \\
\hline
\end{tabular}

Sedangkan ciri-ciri kepribadian yang akan digunakan untuk mengidentifikasi kepribadian adalah seperti berikut ini:

\begin{tabular}{|l|l|}
\multicolumn{1}{|c}{ Tabel 2. Ciri-Ciri Kepribadian } \\
\hline Kode & \multicolumn{1}{|c|}{ Ciri-Ciri Kepribadian } \\
\hline C01 & Seseorang yang mudah berpikir positif \\
\hline C02 & Seseorang yang mudah berpikir negatif \\
\hline C03 & $\begin{array}{l}\text { Seseorang yang banyak bicara daripada } \\
\text { mendengarkan }\end{array}$ \\
\hline C04 & $\begin{array}{l}\text { Seseorang yang mudah berteman dan } \\
\text { mudah berbaur }\end{array}$ \\
\hline C05 & Seseorang yang penuh semangat \\
\hline C06 & Seseorang yang penuh rasa ingin tahu \\
\hline 007 & $\begin{array}{l}\text { Seseorang yang menyenangkan dan } \\
\text { selalu terlihat ceria }\end{array}$ \\
\hline
\end{tabular}




\begin{tabular}{|c|c|}
\hline $\mathrm{C} 08$ & $\begin{array}{l}\text { Seseorang yang menyukai hiburan dan } \\
\text { membuat orang lain terhibur }\end{array}$ \\
\hline C09 & $\begin{array}{l}\text { Seorang yang mampu meyakinkan orang } \\
\text { lain dengan logika dan fakta }\end{array}$ \\
\hline $\mathrm{C} 10$ & Seseorang yang berkemauan tegas dan kua \\
\hline $\mathrm{C} 11$ & $\begin{array}{l}\text { Seseorang yang sangat memerlukan } \\
\text { perubahan }\end{array}$ \\
\hline $\mathrm{C} 12$ & Seseorang yang berbakat memimpin \\
\hline $\mathrm{C} 13$ & $\begin{array}{l}\text { Seseorang yang melakukan sesuatu yang } \\
\text { berorientasi tujuan }\end{array}$ \\
\hline $\mathrm{C} 14$ & $\begin{array}{l}\text { Seseorang yang mudah percaya diri dan } \\
\text { mandiri }\end{array}$ \\
\hline $\mathrm{C} 15$ & $\begin{array}{l}\text { Seseorang yang mudah tersinggung dan } \\
\text { sensitif }\end{array}$ \\
\hline $\mathrm{C} 16$ & $\begin{array}{l}\text { Seseorang yang penuh pikiran dan suka } \\
\text { menganalisa }\end{array}$ \\
\hline $\mathrm{C} 17$ & $\begin{array}{l}\text { Seseorang yang suka membuat rencana } \\
\text { dan terjadwal }\end{array}$ \\
\hline $\mathrm{C} 18$ & $\begin{array}{l}\text { Seseorang yang menuntut kesempurnaan } \\
\text { (perfeksionis dan idealis) }\end{array}$ \\
\hline C19 & $\begin{array}{l}\text { Seseorang yang menyukai detail terhadap } \\
\text { hal kecil maupun besar }\end{array}$ \\
\hline $\mathrm{C} 20$ & $\begin{array}{l}\text { Seseorang yang cerewet dan suka } \\
\text { mengkritik }\end{array}$ \\
\hline $\mathrm{C} 21$ & $\begin{array}{l}\text { Seseorang yang cinta damai serta } \\
\text { menghindari segala bentuk kekacauan }\end{array}$ \\
\hline $\mathrm{C} 22$ & Seseorang yang rendah hati \\
\hline $\mathrm{C} 23$ & Seseorang yang penurut dan toleran \\
\hline $\mathrm{C} 24$ & Seseorang yang pemalu dan pendiam \\
\hline $\mathrm{C} 25$ & Seseorang yang penakut \\
\hline $\mathrm{C} 26$ & Seseorang yang sabar dan ramah \\
\hline
\end{tabular}

\section{HASIL DAN PEMBAHASAN}

\section{Kaidah Produksi (Rule)}

Kaidah yang digunakan sebagai basis pengetahuan dalam sistem pakar identifikasi kepribadian dituliskan dalam bentuk jika-maka (IF-THEN). Kaidah ini dapat dikatakan sebagai hubungan impliksi bagian premise (jika) dan bagian konklusi (maka). Adapun basis aturan disajikan dalam aturan-aturan yang berbentuk pasangan keadaan aksi (condition-action) dalam bentuk pohon keputusan seperti berikut ini:

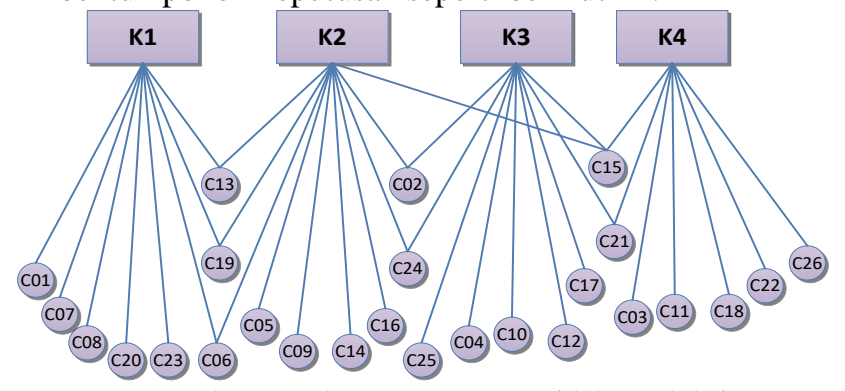

Gambar 2. Pohon Keputusan Kaidah Produksi

Certainty Factor digunakan untuk memberikan tingkat keyakinan terhadap hasil perhitungan, karena seorang pakar sering menganalisis informasi yang ada dengan memberikan faktor ketidakpastian. Dalam sistem pakar ini, setiap jawaban dari pengguna akan memiliki bobotnya masing-masing untuk mendapatkan faktor kepastian.

Table 3. Bobot Nilai MB

\begin{tabular}{|l|c|}
\hline \multicolumn{1}{|c|}{ Keterangan } & Nilai MB \\
\hline Tidak & 0 \\
\hline Sedikit Yakin & $0.40-0.74$ \\
\hline Cukup yakin & $0.75-0.89$ \\
\hline Yakin & $0.90-0.99$ \\
\hline Sangat yakin & 1.0 \\
\hline
\end{tabular}

Table 4. Bobot Nilai MD

\begin{tabular}{|l|l|}
\hline Keterangan & Nilai MD \\
\hline Tidak Yakin & $0-0.02$ \\
\hline Sedikit Yakin & $0.03-0.05$ \\
\hline Yakin & $0.06-0.08$ \\
\hline Sangat Yakin & $0.09-0.10$ \\
\hline
\end{tabular}

\section{Studi Kasus}

Seorang pendidik melakukan identifikasi terhadap salah seorang peserta didik dengan tujuan agar pendidik dapat lebih memahami dan menemukan solusi bagaimana mendidik peserta didik tersebut. Pendidik tersebut memilih ciri-ciri peserta didik yang akan diidentifikasi tersebut seperti berikut ini.

$\begin{array}{lll}\text { C01 } & \text { MB [0.8] } & \text { MD [0.04] } \\ \text { C06 } & \text { MB [0.2] } & \text { MD [0.02] } \\ \text { C07 } & \text { MB [0.8] } & \text { MD [0.02] } \\ \text { C08 } & \text { MB [0.7] } & \text { MD [0.04] } \\ \text { C13 } & \text { MB [0.9] } & \text { MD [0.00] } \\ \text { C19 } & \text { MB [0.2] } & \text { MD [0.00] }\end{array}$

Kombinasi Nilai MB berdasarkan masing-masing ciriciri kepribadian diatas adalah sebagai berikut:

$$
\begin{aligned}
& \mathrm{CF}[\mathrm{HE}] 1,2 \mathrm{~B}=\mathrm{MB} 1+(\mathrm{MB} 2 *(1-\mathrm{MB} 1)) \\
& \mathrm{CF}[\mathrm{HE}] 1,2 \mathrm{~B}=0,8+(0,2 *(1-0,8)) \\
& \mathrm{CF}[\mathrm{HE}] 1,2 \mathrm{~B}=0,8+0,04 \\
& \mathrm{CF}[\mathrm{HE}] 1,2 \mathrm{~B}=0,84 \text { old } 1 \\
& \mathrm{CF}[\mathrm{HE}] \text { old } 1,3 \mathrm{~B}=\mathrm{MB} \text { old } 1+(\mathrm{MB} 3 *(1-\mathrm{MB} \text { old } 1)) \\
& \mathrm{CF}[\mathrm{HE}] \text { old } 1,3 \mathrm{~B}=0,84+(0,8 *(1-0,84)) \\
& \mathrm{CF}[\text { HE }] \text { old } 1,3 \mathrm{~B}=0,84+0,128 \\
& \mathrm{CF}[\mathrm{HE}] \text { old } 1,3 \mathrm{~B}=0,968 \text { old } 2 \\
& \mathrm{CF}[\mathrm{HE}] \text { old } 2,4 \mathrm{~B}=\mathrm{MB} \text { old } 2+(\mathrm{MB} 4 *(1-\mathrm{MB} \text { old } 2)) \\
& \mathrm{CF}[\mathrm{HE}] \text { old } 2,4 \mathrm{~B}=0,968+(0,7 *(1-0,968)) \\
& \mathrm{CF}[\mathrm{HE}] \text { old } 2,4 \mathrm{~B}=0,968+0,0224 \\
& \mathrm{CF}[\mathrm{HE}] \text { old2,4B }=0,9904 \text { old } 3 \\
& \mathrm{CF}[\mathrm{HE}] \mathrm{old} 3,5 \mathrm{~B}=\mathrm{MB} \text { old } 3+(\mathrm{MB} 5 *(1-\mathrm{MB} \text { old } 3)) \\
& \mathrm{CF}[\mathrm{HE}] \mathrm{old} 3,5 \mathrm{~B}=0,9904+(0,9 *(1-0,9904)) \\
& \mathrm{CF}[\mathrm{HE}] \mathrm{old} 3,5 \mathrm{~B}=0,9904+0,00864 \\
& \mathrm{CF}[\mathrm{HE}] \text { old3,5B }=0,99904 \text { old } 4 \\
& \mathrm{CF}[\mathrm{HE}] \text { old4 }, 6 \mathrm{~B}=\mathrm{MB} \text { old4 }+(\mathrm{MB} 6 *(1-\mathrm{MB} \text { old4 })) \\
& \mathrm{CF}[\mathrm{HE}] \text { old } 4,6 \mathrm{~B}=0,99904+(0,2 *(1-0,99904)) \\
& \mathrm{CF}[\mathrm{HE}] \mathrm{old} 4,6 \mathrm{~B}=0,99904+0,000192 \\
& \mathrm{CF}[\mathrm{HE}] \text { old } 4,6 \mathrm{~B}=0,999232 \text { old } 5
\end{aligned}
$$

Kombinasi Nilai MD berdasarkan masing-masing ciriciri kepribadian adalah sebagai berikut:

$\mathrm{CF}[\mathrm{HE}] 1,2 \mathrm{D}=\mathrm{MD} 1+(\mathrm{MD} 2 *(1-\mathrm{MD} 1))$

$\mathrm{CF}[\mathrm{HE}] 1,2 \mathrm{D}=0,04+(0,02 *(1-0,04))$

$\mathrm{CF}[\mathrm{HE}] 1,2 \mathrm{D}=0,04+0,0192$

$\mathrm{CF}[\mathrm{HE}] 1,2 \mathrm{D}=0,0592$ old 1

$\mathrm{CF}[\mathrm{HE}]$ old1 $3 \mathrm{D}=\mathrm{MD}$ old $1+(\mathrm{MD} 3 *(1-$ MDold 1$))$

$\mathrm{CF}[\mathrm{HE}]$ old $1,3 \mathrm{D}=0,0592+(0,02 *(1-0,0592))$ 


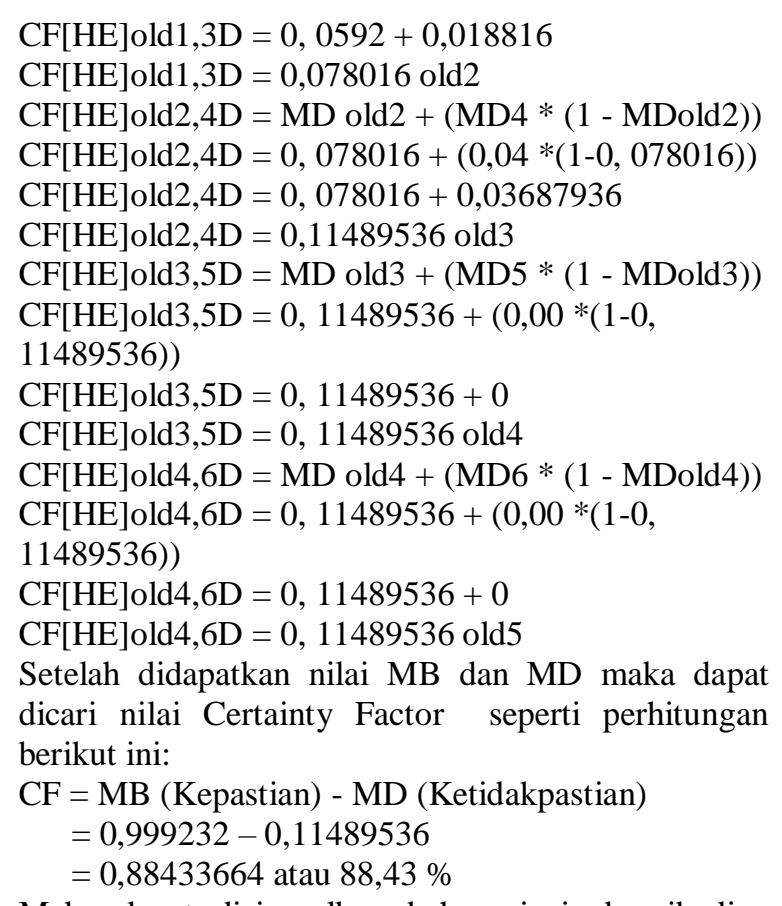

Maka dapat disimpulkan bahwa jenis kepribadian "Choleric" yang teridentifikasi adalah sebesar 88,43 $\%$.

\section{Usecase Diagram}

Use case diagram menggambarkan interaksi yang terjadi antara user dan sistem sehingga dapat dipahami dengan lebih mudah. Berikut ini adalah use case diagram sistem identifikasi kepribadian dengan metode Certainty Factor.

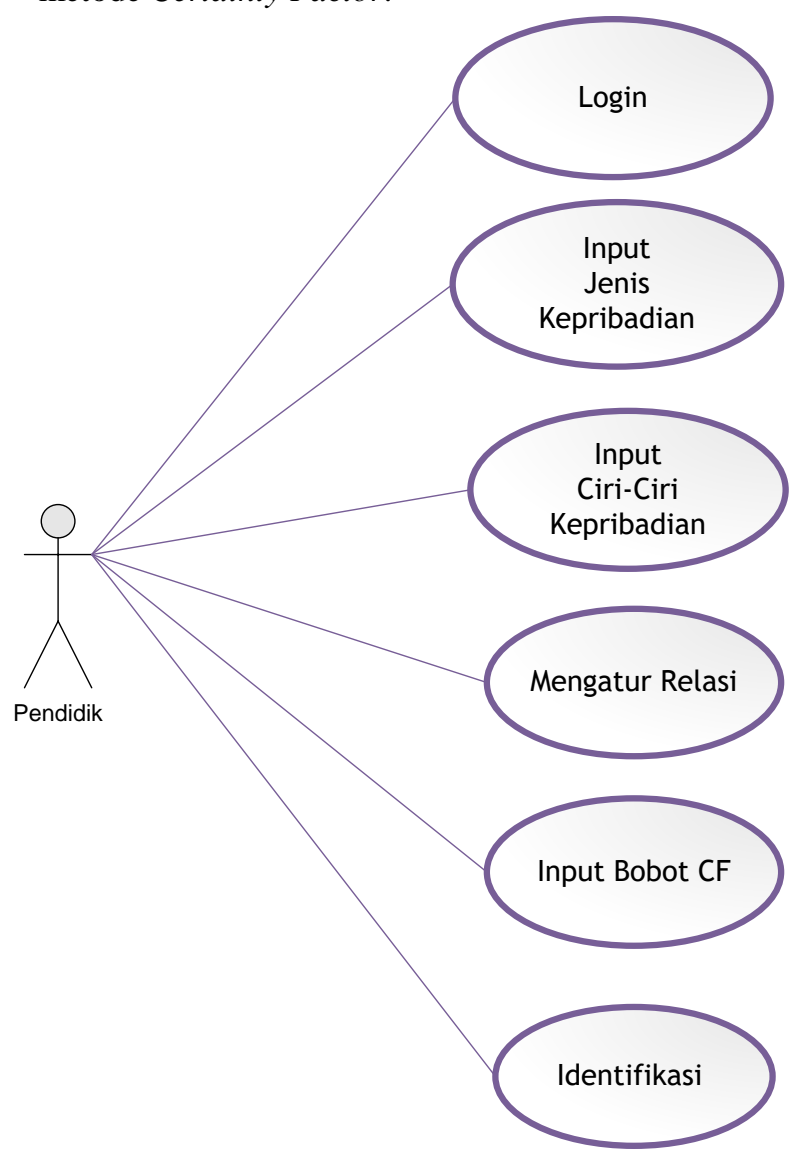

Gambar 3. Use Case Diagam

\section{Entity Relationship Diagram}

Entity Relationship Diagram dari sistem identifikasi kepribadian ini adalah sebagai berikut:

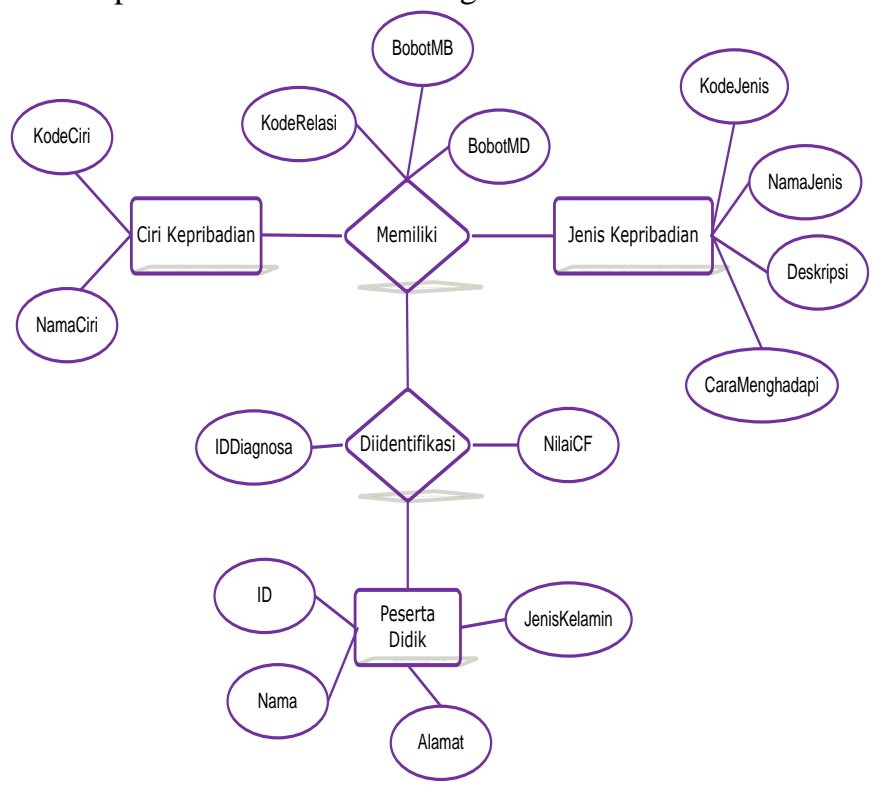

Gambar 4. Entity Relationship Diagram

\section{KESIMPULAN}

Berdasarkan pembahasan yang telah dijelaskan diatas, maka kesimpulan yang dapat diambil adalah sistem berhasil diimplementasikan menggunakan metode certainty factor dan juga dapat mengidentifikasi tipe kepribadian peserta didik berdasarkan ciri-ciri kepribadian. Sedangkan saran dari penulis untuk pengembangan selanjutnya adalah memperbanyak ciri-ciri kepribadian untuk memperoleh hasil yang lebih akurat lagi dan disarankan untuk melakukan pembuatan sistem berbasis online, sehingga identifikasi kepribadian dapat dilakukan oleh siapa saja.

\section{REFERENSI}

[1] A. Sulistiono, "Pengaruh Kepribadian Siswa Dan Persepsi Siswa Tentang Model Pembelajaran Guru Terhadap Prestasi Belajar Siswa Kelas Xi Smk Gondang Pada Pembelajaran Matematika," vol. 3, no. 2, pp. 7484, 2015.

[2] T. G. Laksana and D. I. Permata, "Identifikasi Kepribadian Siswa Melalui Penerapan Sistem Pakar Dengan Teknik Forward Chaining," Pros. Semin. Nas. Pendidik. Tek. Inform. (SENAPATI 2016), no. Senapati, pp. 265-273, 2016.

[3] W. Winarso, "Perbedaan Tipe Kepribadian terhadap Sikap Belajar Matematika Siswa Kelas X SMA Islam Al-Azhar 5 Cirebon," J. Sainsmat, vol. IV, no. 1, pp. 6780, 2015, doi: 10.18592/jpm.v2i1.1170.

[4] N. A. Putri, "Sistem Pakar Untuk Mengidentifikasi Kepribadian Siswa Menggunakan Metode Certainty Factor Dalam Mendukung Pendekatan Guru," J. Inf. Technol. Comput. Sci., vol. 1, no. 1, 2018.

[5] C. Adiwihardja, P. S. Mahadewi, J. T. Komputer, F. T. Informasi, U. Bina, and S. Informatika, "Perapan Metode Certainty Factor Pada Aplikasi Pakar Seleksi Tes Kepribadian Calon Karyawan," semanTIK, vol. 5, no. 2, pp. 219-230, 2019.

[6] Adi Suwarno, Ishak Husein, and Sabar Hanadwiputra, 
"Perbandingan Metode Certainty Factor (CF) Dengan Metode TOPSIS Untuk Mendiagnosa Gangguan Kepribadian Pada Remaja," J. Pelita Teknol., vol. 15, no. 1 , pp. 56-67, 2020.

[7] P. V. Andreyana, I. N. Piarsa, and P. W. Buana, "Sistem Pakar Analisis Kepribadian Diri dengan Metode Certainty Factor," J. Ilm. Merpati (Menara Penelit. Akad. Teknol. Informasi), vol. 3, no. 2, pp. 78-86, 2015.

[8] O. Putri and K. Budayawan, "Sistem Pakar Identifikasi Kepribadian Remaja dengan Metode Forward Chaining dan Certainty Factor," VoteTEKNIKA J. Vocat. Tek. ..., vol. 8, no. 4, 2020.

[9] P. B. M. Noor, Ekojono, and N. Santoso, "Sistem Pakar Diagnosis Tipe Kepribadian Menggunakan Metode Certainty Factor," Semin. Inform. Apl. Polinema, no. 09, 2016. 